\section{TEACHING AND TEACHER EDUCATION}

www.elsevier.com/locate/tate

\title{
Using an analogy in the introduction of a portfolio
}

\author{
Jan van Tartwijk ${ }^{\mathrm{a}, *}$, Martine van Rijswijk ${ }^{\mathrm{b}}$, Hanneke Tuithof ${ }^{\mathrm{b}}$, Erik W. Driessen ${ }^{\mathrm{c}}$ \\ ${ }^{a}$ ICLON-Leiden University Graduate School of Teaching, P.O. Box 9555, 2300 RB Leiden, The Netherlands \\ ${ }^{\mathrm{b}}$ IVLOS-Institute of Education, Utrecht University, P.O. Box 80127, 3508 TC Utrecht, The Netherlands \\ ${ }^{\mathrm{c}}$ Department of Educational Research and Educational Development, Faculty of Medicine, Maastricht University, \\ P.O. Box 616, 6200 MD Maastricht, The Netherlands
}

Received 29 January 2007; received in revised form 11 October 2007; accepted 1 November 2007

\begin{abstract}
Students in many teacher education programmes experience confusion about portfolios. This study investigated whether using an analogy in the introduction of a portfolio helps teacher education students understand both the purpose of a portfolio and how to compile it. It was also investigated whether these students' understanding correlates with their appreciation of portfolios. In the analogy, portfolios were compared with job application letters, curricula vitae and the references that are common in selection procedures for new employees. This analogy was helpful in promoting students' understanding. Their understanding correlated with their appreciation of this instrument.
\end{abstract}

(C) 2007 Elsevier Ltd. All rights reserved.

Keywords: Portfolio; Analogy; Teacher education

\section{Introduction}

In the last decades a shift in emphasis has taken place in many teacher education programmes from learning within the walls of the teacher education institutes towards learning from everyday practice in schools (Stokking, Leenders, de Jong, \& Van Tartwijk, 2003). To be able to assess and support the professional development of teacher education students in everyday practice, teacher educators need information about how these teaching candidates perform in schools (Darling-Hammond \&

\footnotetext{
*Corresponding author. Tel.: + 31715273845 ; fax: +31715275342

E-mail addresses: jtartwijk@iclon.leidenuniv.nl (J. van Tartwijk), m.m.vanrijswijk@uu.nl (M. van Rijswijk), h.tuithof@uu.nl (H. Tuithof), e.driessen@educ.unimaas.nl (E.W. Driessen).
}

Snyder, 2000; Shulman, 1998) and about how they learn from their experiences (Korthagen, Kessels, Koster, Lagerwerf, \& Wubbels, 2001). Portfolios have the potential to provide this information. Information about how teacher education students perform can be deduced from the videos, lesson plan, evaluations and other artefacts that they bring together in their portfolios. Information about how they learn from their experiences can be deduced from the way they reflect on these experiences in their portfolios.

Portfolios are used in a wide variety of educational contexts in which they serve many purposes and take many forms (van Tartwijk, Driessen, van der Vleuten, \& Stokking, 2007). For example, portfolios are used in teacher assessment programmes in which in-service teachers provide evidence of their competence such as lesson plans, 
tests that were administered to their pupils and the results of these tests, written evaluations, results of questionnaires and videotapes of lessons. Sometimes teachers are asked to compile portfolios according to guidelines that are highly prescriptive about the content of the portfolio and how it should be presented (Peterson, 1995). Sometimes teachers have more freedom in making choices and are provided with a list of documents and other artefacts that they might include in their portfolio that is "intended to be suggestive rather than exhaustive" (Wolf, 1991). In the last 15 years, the use of portfolios has become commonplace in teacher education as well (Zeichner \& Wray, 2001). Here too, they are used as tools for assessment (Darling-Hammond \& Snyder, 2000; Pecheone \& Chung, 2006; Tillema \& Smith, 2007). But portfolios can also be used as instruments to promote reflective practice (Borko, Michalec, Timmons, \& Siddle, 1997). They are, for instance, used to stimulate students to reflect on specific themes that are relevant for their development (Mansvelder-Longayroux, Beijaard, \& Verloop, 2007), to document learning and growth in a specific project (Wade \& Yarbrough, 1996) or to encourage students to explore their roles as teachers and professional identities as novice teachers and reflect on their student teaching experience (Borko et al., 1997). Usually written reflections are included alongside documents and other artefacts in those portfolios.

Although in theory a portfolio can be an important instrument for teacher education, in practice working with portfolios is complicated and can easily lead to frustration. Zeichner and Wray (2001) refer to a number of emerging issues in the use of portfolios in teacher education. An example of such an issue is whether or not a single portfolio can serve multiple purposes such as stimulating reflective practise and authentic assessment (Snyder, Lippincott, \& Bower, 1998; Tillema \& Smith, 2007; Wolf \& Dietz, 1998). Another issue that is mentioned by Zeichner and Wray is how to foster student ownership of the portfolios. Leaving the construction of the portfolio mainly to teacher education students can easily lead to superficial reflection about teaching and limited evidence on which to base an assessment. On the other hand, tightly prescribing the content of the portfolio might easily lead students to experience the portfolio as something that is imposed on them, with negative consequences for their feeling of ownership of their portfolio and their willingness to invest time in compiling it (Borko et al., 1997; Wade \& Yarbrough, 1996).

An issue that is not mentioned by Zeichner and Wray but that is often described in the literature about the use of portfolio in teacher education, is that the introduction of portfolios often leads to confusion. For instance, Wade and Yarbrough (1996) report that in their experiments many students became frustrated about the portfolio assignment. According to these authors, a key factor in these students' struggles was the way the portfolio assignment was presented and explained in class. Because of a lack of experience with this instrument and because the expectations that students had about educational coursework were very distant from working with portfolios, students had no or few ideas about how to create one. As a consequence, they did not invest enough time and energy in the portfolio construction process. Carroll, Potthoff, and Huber (1996) investigated the perceptions of 30 teacher educators about the purposes and the use of a portfolio after these educators had worked with portfolios for 3 years. Although these educators had 3 years of experience, they were still striving for a clear and shared understanding of the portfolio's purpose. Anderson and DeMeulle (1998) questioned teacher educators representing 24 teacher education programmes about their experiences with portfolios. These teacher educators indicated that understanding of the concept of portfolio was a major problem when introducing portfolios. The purposes of working with portfolios, how to proceed and their added value were often unclear to students and teacher educators. Darling (2001) interviewed 12 students about their experiences with a portfolio assignment. She found that the portfolio assignment raised questions for many students. One of the students she interviewed told her that working with a portfolio was so distant from her earlier experiences in education that it almost felt intimidating. Breault (2004) described dissonance in the beliefs and interpretations of, on the one hand, students and, on the other hand, teacher educators about the purposes, values and practice of working with portfolios. It turned out to be difficult for teacher educators to make it clear to students what a portfolio is, what the purposes of working with a portfolio are, what the added value of working with a portfolio is and how compiling, discussing and assessing a portfolio works. 
To make productive use of portfolios in everyday teacher education, it is important that the users understand the purpose of using a portfolio and how to compile it. A clear introduction of the portfolio will have a positive effect on students' comfort with working with a portfolio and prevent confusion and frustration (Duque et al., 2006). An obvious option is to use a highly prescriptive instruction. An example is the approach advocated by Peterson (1995) for the assessment of teachers. Teachers who have to compile a portfolio such as the one proposed by Peterson, will get a list of documents, videos and other artefacts that they should include in their portfolio. They will also receive very precise instructions about how to present these artefacts. Peterson prefers the label "teacher dossier" for this highly pre-structured portfolio. An advantage of Peterson's portfolio is that it is very clear to the teachers how to proceed and what is expected from them. Furthermore, it is relatively easy to assess these portfolios in a reliable way using fixed standards. A disadvantage is that teachers compiling these portfolios have little or no freedom to give the portfolio a personal touch. As mentioned earlier, this will probably have negative consequences for their feeling of ownership of their portfolio in their willingness to invest time in the portfolio. Krause (1996) experimented with asking students to bring items, gathered in a bag, to a reflective session that represented something important about them as a person (she referred to the activity as My life in a bag). Then she asked students to write down why a specific item was important. During the activity she made explicit connections with the portfolio that students would have to produce. Krause found that this instruction contributed to the students' understanding of a portfolio process that focuses on selecting, assembling and reassembling documents.

Another option to stimulate the understanding of portfolios is to use analogies when introducing them. In secondary education, analogies are often used to clarify new concepts and phenomena (Hulshof \& Verloop, 2005; Orgill \& Bodner, 2004). An analogy is generally regarded as a comparison between two domains of knowledge. One of these domains is familiar, the other is not. The familiar domain is called the analogue domain, the unfamiliar domain is referred to as the target domain. An adequate analogy can be a powerful tool to help students to give meaning to new abstract information. The use of analogies fits in a constructivist perspective on learning, in which learning processes are regarded as a search for similarities between what is already known and new knowledge that needs to be learned (Duit, Roth, Komorek, \& Wilbers, 2001). Using an analogy in the introduction of a portfolio, provides the opportunity to select a specific analogy that fits best with a specific portfolio approach.

The study described here explores the use of an analogy in the introduction of a portfolio. It is aimed at answering the question whether using an analogy when introducing a portfolio helps students understand both what the purposes are of working with a portfolio and how to compile it. The correlation between the students' understanding and their appreciation of the portfolio and its use is also investigated.

\section{Context}

\subsection{The programme}

This study was carried out in the teacher education programme of a research university in the Netherlands. In this programme, students who already have a masters degree or comparable experience are trained as teachers for secondary education in one year. Each year about 130-200 students enroll in the programme. This programme follows the so-called realistic approach (Korthagen et al., 2001). Students spend half of their time working in schools in which they carry out the tasks of a teacher. During the year, their autonomy in carrying out these tasks increases. At school, they are supervised by an experienced teacher. Working in schools is combined with meetings at the university. These meetings are chaired by two teacher educators during the entire course. During these meetings, students share and discuss their experiences in the schools and link them to the relevant theory (Tigchelaar \& Korthagen, 2004). In addition to these meetings, students have at least three individual meetings with one of these two teacher educators. In these individual meetings, the student's performance and development towards the required level of competence are discussed. In these discussions, six competencies are distinguished that students are required to master to be certified at the end of the programme. These competencies are presented to the students as six professional roles that they should be able to fulfil as a subject teacher, as a planner and coach of learning, as a guide and 
counsellor, as classroom manager, as teacher beyond the class and finally, as a reflective teacher and researcher. The professional identity that students are developing (Beijaard, Meijer, \& Verloop, 2004) and their motivation for the teaching profession are also discussed. This is referred to as the professional profile of the students. Furthermore, the students take a subject-specific teaching and learning course and carry out a small research project during the programme.

\subsection{The portfolio}

The portfolio is a crucial source of information for the individual meetings. The discussions in the first two meetings result in a personal development plan for the coming period. In the last meeting, the participants discuss whether the competencies of the student are sufficient for certification. Based on the information provided in the portfolio, the discussions in this last meeting and the comments of the supervising teacher in the school, and the criteria described in the institutions' rubrics, the teacher educator whether or not to recommend certification.

To prepare for each individual meeting with the teacher educator, the students describe and reflect on their performance and development in the previous period. These descriptions and reflections are structured according to the six competencies that the students should develop in order to be certified at the end of the programme. The students also include a short description in their portfolio about their professional profile. Finally, they include an overview of their previous experience and a $\log$ of their experiences both in the school and at the university in their portfolio. The students must refer in their written reflections to documents and other artefacts in the portfolio in order to systematically demonstrate their claims. The students are provided with a list of appropriate items that they might include in their portfolio in order to accomplish this. This list is intended to be suggestive rather than exhaustive (Wolf, 1991). Examples of items on this list are plans for a unit of instruction, lesson-plans, tests that were used, evaluations by the supervising teacher, the results of an evaluative questionnaire administered to the students in the class, and photographs and (fragments from) videotapes of instruction. Although students are free to select the artefacts that they include in their portfolio, they are informed that they should be able to prove their competence in the various teacher roles in order to get certified at the end of the programme. Some artefacts may better demonstrate competence in specific roles than others. An example is the report of the results of the Questionnaire on Teacher Interaction (Wubbels, Brekelmans, den Brok, \& van Tartwijk, 2006) that all students administer in their classes. This questionnaire is designed to help reveal the pupils' perceptions of the interpersonal style of their teacher. The results shed light upon the character of the classroom communication processes and therefore the teacher's success in classroom management. Although students are not obliged to include the report about the results of this questionnaire in their portfolio to prove their competence as a classroom manager, assessors will certainly ask why this is not done.

The portfolio takes the form of a website that the students can edit themselves using a standard HTML editor (e.g. Macromedia's Dreamweaver or Microsoft FrontPage). This website consists of a welcome page, pages for the six roles, a page for the professional profile and a page on which an overview of previous experience and the log can be found. The students use hyperlinks to refer from these pages to their artefacts. To make a start with their portfolio, students are provided with a portfolio template on a CD or diskette. This template contains all the labelled pages of the portfolio website and hyperlinks between them with a default layout and headings, but no other content.

\subsection{The analogy}

In the period before an analogy was used for the introduction of the portfolio, the portfolio introduction consisted of a written instruction in which students were informed that the portfolio was to be used both for planning their development and for assessment. The instruction also contained a list of artefacts that could be included in the portfolio and the suggestions for the organization of the portfolio. However, in evaluations of working with the portfolio, teacher educators complained that the portfolios that students compiled differed considerably in size, structure and content. Sometimes portfolios contained too little information to be useful for coaching or assessment, or contained so many reflections and artefacts that it took teacher educators several hours to study the portfolio. Very often the students deviated from the structure that 
was suggested, which resulted in teacher educators having to invest time to discover their way in these portfolios. In many portfolios, artefacts were missing that were important to understand the students' development in specific roles, such as the Questionnaire on Teacher Interaction for the role of the teacher as classroom manager. When teacher educators and the developers of the portfolios discussed this with the students, the students complained that the purpose of using a portfolio and how to proceed when compiling one was unclear to them. This is consistent with the comments of many student teachers described in the literature referred to in the introduction of this article (e.g. Darling, 2001; Wade \& Yarbrough, 1996).

In this period, teacher educators also organized workshops for the students in which they were trained in writing a job application cover letter and a Curriculum Vitae (CV). These workshops were not aimed at showing students the purpose and use of portfolios, but students were encouraged to use their portfolios in practice interviews that were part of these workshops. It was remarkable that almost all students were familiar with the conventions about the form and content of job application letters, CVs and references from former employers and teachers. This recognition of familiarity generated the idea to use the documents that are used in job application procedures and the references as the analogue domain in an analogy that could be used for the introduction of portfolio. In this analogy, the target domain was the portfolio and its use in teacher education.

The first similarity between the analogue and the target domain in this analogy is the character of the assessment. In both domains, the people being assessed provide the information that is used for the assessment. They are not tested, but are asked to prove their level of competence. A second similarity is that both an applicant in a selection procedure and a student in a portfolio use a combination of reflections and evidence. A third similarity is that both portfolios and the combination of letters of application, CVs and references are difficult to assess in a standardized manner. Experiences described in portfolios and CVs differ from person to person and the contexts in which artefacts are gathered differ as well. A fourth similarity between the two domains is that it is desirable to stick to explicit or implicit conventions about structure and format. If the applicant or the student compiling a portfolio did not follow those conventions, people who are studying the portfolio or the job application letter and CV would have to discover their way in each new document. However, a strict uniform layout of these documents is not required. Applicants and students do have the opportunity to add a personal touch and show something of their style and preferences. Slight deviations from the conventions about the job application letter and $\mathrm{CV}$ or the portfolio so that it suits the own circumstances of the applicant or student better usually are no problem either.

\subsection{The introduction of the portfolio}

Teacher educators introduce the portfolio to the students at the beginning of the teacher education programme. For this purpose, an instruction on paper is provided. The students also get a CD or diskette with the portfolio template. The analogy between the selection procedure and working with a portfolio is introduced at the start of the instruction on paper:

When you apply for a new job, you usually send a letter of application and a curriculum vitae (CV) to your potential employer. In your CV you give an overview of your experience. In your letter you write why you are motivated for the job and how your experience relates to the requirements for the job which are mentioned in the advertisement. In the subsequent interview you may be asked for a list of persons for whom you have worked or who have taught you. These references can confirm what you have written in your letter and $\mathrm{CV}$. In essence, you can regard the portfolio as a combination of a $\mathrm{CV}$, a letter of application, and references in a selection procedure for a new job. Like in a CV, you give an overview of what you have done in your portfolio. Like in a letter of application, you introduce yourself as a professional, you write why you are motivated for the job, and to what extent your competencies match the requirements for the job. Furthermore, in a portfolio, you support what you have written with what others think of you and with other kinds of evidence. You can compare this with how references in a selection procedure are used.

The first lines of the letter of application are compared with the description of the professional 
profile that students are to provide on the profile page of the portfolio.

The profile-page in the portfolio can be compared with the introduction to your letter of application. Here you introduce yourself as a professional and a person, and you explain why you are motivated for the job. Describe here what you want to achieve as a teacher, what your ideas are about education, and why the teaching profession suits you as a person.

The reflections on development in the six teacher roles that students are to provide on the role pages of the portfolio, are compared with the part of the letter of application in which the applicant reflects on how his or her competence matches the requirements. In the instruction, the description of the six competencies that the students should develop in order to be certified at the end of the course are presented to the students in the form of a job advertisement (Fig. 1).

In the instruction on paper, the students are asked to provide an overview of their experiences both before and during the teacher education course on the $\mathrm{CV}$ page of their portfolio.

Like in a $\mathrm{CV}$ that is used in a selection procedure, on the CV-page of the portfolio you should give an overview of your previous training, your teaching experience, and other relevant experience both before and during teacher education. (...)

We are looking for:

A subject teacher who is capable of formulating an explicit vision of her subject and its place in society. She also has insight into the structure of the curriculum of the subject and its goals. She knows how students acquire knowledge and comprehension of her subject. She is able to translate this vision, insight, and knowledge into effective and attractive lessons.

A planner and coach of learning who can plan learning activities, lessons, and the longterm development of the students, taking into consideration goals that she has established herself. She can also carry out these plans, showing that she is capable of using various forms of instruction adequately, can adjust plans if necessary, and is able to communicate the why and how of her lessons to students. She is also able to handle differences between students. We also expect her to be able to evaluate and assess the progress of her students.

A guide and counselor who can create a safe learning environment where children feel valued and respected. She can express her beliefs about bringing up children and can translate this into concrete classroom behaviour. She can counsel individual learners about their problems. She can apply theories about child development and behaviour to her work at school.

A classroom manager who is aware of and can work with communication patterns and interaction in the classroom. She can create a good relationship with individual learners and a class. She can use a repertoire of different techniques to deal with classroom problems and/or discipline, with a whole class and with individual learners.

A teacher beyond the class who is aware of and involved in the school as an organization. She can work as a member of a school team and can fulfil duties which go beyond the confines of the lesson, the classroom, and her subject. She is capable of developing expertise in some learning and behavioural problems.

A reflective teacher and researcher who is responsible for her own professional growth, which means that she can reflect upon and analyze her own behaviour in order to improve. She can carry out practical classroom-based research and thus contribute to the improvement of education within her school.

Fig. 1. Job advertisement. 
The artefacts that are to be included in the portfolio as evidence are compared with the references in a selection procedure in the instruction. At this point, the instructions also pointed out that the analogy has its limitations:

In a portfolio, you support your descriptions and analyses by referring to what others have to say about your functioning. You can compare this with the references from a job selection procedure. However, you go much further in supporting your reflections and overviews in your portfolio than you do in a selection procedure. In your portfolio, you not only refer to what other people say about your competence, but you also use various materials to demonstrate this. Examples are lesson plans, teaching materials, notes, logs, reports, materials that your students have made, video recordings, and photos.

\section{Method}

To determine whether using an analogy in the introduction of a portfolio helps students understand what the purposes are of working with a portfolio and how to compile it, and to find out whether understanding of the portfolio correlates with appreciation of the use of the portfolio, data were collected from both students and teacher educators. The teacher educators were asked to participate in the experiments with the new introduction on a voluntary basis. They were selected because they had shown interest in helping to improve the process of working with the portfolio in a regular meeting of teacher educators about the development of the curriculum. Teacher educators worked with groups of 10 to 20 student teachers. If the groups were larger, pairs of teacher educators worked with the groups.

A questionnaire was used to gather data among the students. The questions were about students' understanding of various aspects of the portfolio and their appreciation of the portfolio and its use in the programme. The questions in this questionnaire took the form of a five-point Likert-type scale. Six of these questions were aimed at gathering information about the students' understanding of the portfolio. Four questions were used to gather information about their appreciation of working with this instrument. To get more background information, students were asked to describe positive and negative aspects of working with a portfolio in the programme and to explain their answers. Space was also provided for comments in the questionnaire. For 3 consecutive years, the questionnaire was completed by the students in the final group meeting with their teacher educators. In year 1 and year 2, three groups participated. In year 3 the use of the new introduction was evaluated in five groups. A total number of 130 students from 11 groups completed the questionnaire (year 1, three groups, $n=37$; year 2, three groups, $n=38$; year 5 , five groups, $n=55$ ). This is $70 \%$ of the 185 students that belonged to these groups and, for each year, about $30 \%$ of the total number of students that enrolled in the programme. The response rate within the groups varied from $60 \%$ to $90 \%$. Nonresponse was due to not being able to attend the final meeting because of other obligations. To determine whether the students' understanding correlated with the appreciation of the portfolio and its use, we combined the items about the students' understanding in an Understanding scale and the four items about their appreciation of the portfolio in an Appreciation scale. The internal consistencies of both scales were sufficient (alphas of .70 and .74 , respectively).

Semi-structured interviews were conducted with nine teacher educators who supervised groups of students that had worked with the portfolio and that completed the questionnaire in year 1 and in year 3 of the study. In these interviews, the student questionnaire was used as the interview scheme. A report was made of each interview which was submitted to the teacher educator, asking for his or her consent of the content of this report.

\section{Results}

In Table 1, the students' mean answers to the questions about their understanding of various aspects of the portfolio are presented. Underneath we describe these results and illustrate them with quotes from students' remarks in the questionnaire and with quotes from the interviews with the teacher educators.

\subsection{Purposes}

Most students found the purposes of making a portfolio clear (question 1, mean 4.1 on a five-point scale), although some of them noted that it took some time before they really understood the purpose of making a portfolio. 
Table 1

The students' mean answers to the questions about students' understanding

\begin{tabular}{|c|c|c|c|c|}
\hline & Year 1 & Year 2 & Year 3 & Total \\
\hline 1. Is the purpose of making a portfolio clear to you? & 3.9 & 4.1 & 4.2 & 4.1 \\
\hline $\begin{array}{l}\text { 2. Do you find the structure of the portfolio (the template) that was provided to you } \\
\text { clear? }\end{array}$ & 3.6 & 3.9 & 4.1 & 3.9 \\
\hline $\begin{array}{l}\text { 3. Is it clear to you what information you should provide on the profile page of the } \\
\text { portfolio? }\end{array}$ & 3.2 & 3.6 & 3.7 & 3.5 \\
\hline $\begin{array}{l}\text { 4. Is it clear to you what information you should provide on the various role pages } \\
\text { of the portfolio? }\end{array}$ & 3.4 & 3.2 & 3.8 & 3.5 \\
\hline 5. Is it clear to you what information you should provide in the CV? & 3.8 & 3.9 & 4.1 & 4.0 \\
\hline 6. Is it clear to you which materials you can include in your portfolio? & 3.8 & 3.5 & 3.8 & 3.7 \\
\hline
\end{tabular}

Scores were made on five-point scales $(1=$ very unclear, $5=$ very clear). Standard deviations varied from .73 to 1.04 .

Only after a couple of months, I really understood the purposes. (Student 19)

According to some teacher educators it was difficult for students to understand the purpose of working with a portfolio, because it implies a new perspective on education.

Rationally, students comprehend what is intended pretty fast. But it takes some time before it really gets through. For many students it is a new perspective on education to which they are not yet accustomed. They have never come across something like this during their careers as students. The terminology associated with this approach, such as portfolio, is new to them as well. (Teacher educator 8)

Teacher educators remarked that many students did not read the instruction thoroughly. Therefore, discussing the portfolio in the group and in the first individual discussion were also important to get the students on the right track.

\subsection{Structure}

The students found the structure of the portfolio clear (question 2, mean 3.9). About a quarter of the students that completed the questionnaire spontaneously referred to the use of a template as something that should certainly remain the way it is.

It gives a clear structure to your story... (Student 69)

The template, the structure, it is clear what it should contain. (Student 80)

A number of students explicitly referred to the freedom of using the template as positive.
(I appreciate) the freedom to tailor it to your own development. (Student 47)

The room for a personal approach should certainly stay the way it is. (Student 130)

The teacher educators did not mind if the students adapted the layout and the style of the portfolio to their own taste and even found this important, because it increased the students' feeling of ownership of the portfolio.

I think the portfolio should become a personal document. They should play with it. I really appreciate that." (Teacher educator 5)

\subsection{Information in the portfolio}

In general, it was clear to the students what kind of information was expected on the $\mathrm{CV}$ pages of the portfolio (question 5, mean 4.0). It was also clear to them which materials (artefacts) could be included in the portfolio (question 6, mean 3.7). The mean answers to the questions whether it was clear what kind of information they should provide on the role pages and the profile page were slightly less positive (questions 3 and 4, both means 3.5).

I think that, at the start of the programme, the roles are not yet clear enough. You don't a have a lot of background. As a consequence, your opinion can change easily. (Student 59)

According to some teacher educators, the kind of information expected for specific roles was probably clear, but overlap between the roles may have caused confusion.

The problem with the roles is that a number of those roles overlap. Examples are the roles of classroom manager and the role of guide and 
counsellor. For both roles, norms and values are an issue. Sometimes this is confusing. (Teacher educator 6)

The topics addressed on the profile page of the portfolio, such as beliefs about teaching and education, professional identity and motivation, were more abstract than the issues addressed in the $\mathrm{CV}$ and on the role pages, which concerned actual tasks in the school. This probably explains why students found it less clear what information they should provide on the profile page.

Certainly at the start of the programme, the information that should be provided on the profile page is relatively vague. This is about relatively abstract issues. (Teacher educator 4 )

\subsection{Appreciation of the portfolio and its use}

In Table 2, the students' mean answers to the questions about the appreciation of the portfolio and its use in the programme are presented.

On average, the students believed that the portfolio provided a reasonable impression of their competence as teachers (question 7, mean 3.4). Providing evidence in the portfolio is important for this.

You are more or less forced to provide evidence of your competence." (Student 74)

The interviews with the teacher educators showed that, in general, the teacher educators were positive about the impression of the students that they got from their portfolios. A number of teacher educators noted that the diversity of the artefacts was important for their impression of the competence of the students. According to some teacher educators, the impression that they got when visiting the student in his or her own school improved the impression of his or her competence.
You see how they communicate with students and colleagues. Whether they are members of the team. How they persevere throughout the entire lesson. (Teacher educator 7)

The students were positive about the discussions about their portfolios with their teacher educators (question 8, mean 3.8). Teacher educators regarded these discussions as crucial for the success of working with a portfolio.

In these discussions the student is heard and seen through his portfolio. That is crucial for the success of the use of the portfolio. Students are also put on the right track in these discussions. (Teacher educator 2)

On average, the students felt that working with a portfolio gave them a better understanding of their strong and weak points (question 9, mean 3.6). Some students wrote that the portfolio stimulated them to reflect on their functioning in school and the class and on their development.

Reflection on competence and development in the portfolio gives you an overview of what you learn during the programme and makes theory concrete. (Student 76)

Keeping track of your own development is important. It is good that you have to think about that yourself. (Student 126)

The teacher educators also found the portfolio a suitable instrument to stimulate students to reflect on their development.

It regulates the process of reflection and in that sense it is certainly functional. (Teacher educator 7)

They are forced to take a better and more detailed look at themselves. That helps them to make explicit what they are good at and where they still have to improve. (Teacher educator 9)

Table 2

The students' mean answers to the questions about their appreciation of the portfolio and its use

\begin{tabular}{|c|c|c|c|c|}
\hline & Year 1 & Year 2 & Year 3 & Total \\
\hline 7. Does the portfolio give a good impression of your competence as a teacher? & 3.4 & 3.3 & 3.6 & 3.4 \\
\hline 8. Was it worthwhile to discuss your portfolio with your teacher educator? & 3.5 & 3.7 & 4.1 & 3.8 \\
\hline $\begin{array}{l}\text { 9. Did working on the portfolio give you a better impression of your strong and } \\
\text { weak points as a teacher? }\end{array}$ & 3.5 & 3.5 & 3.7 & 3.6 \\
\hline 10. Was the time and energy you invested in the portfolio worthwhile? & 3.0 & 3.1 & 3.5 & 3.2 \\
\hline
\end{tabular}

Scores were made on five-point scales $(1=$ very bad, $5=$ very good; or $1=$ not at all, 5 very much; or $1=$ not at all worthwhile, $5=$ very worthwhile). Standard deviations varied from .87 to 1.02 . 
The students also answered the more general question about whether the time and energy they invested in working with the portfolio was worth it. On average, the students answered this question positively (question 10, mean 3.2).

\subsection{Correlations between understanding, appreciation and year of compiling a portfolio}

We established a significant $(p<.001)$ correlation of .51 between the average scores on the items about student understanding, which were combined in the Understanding scale, and the average scores on the four items about student appreciation of working with a portfolio that were combined in the Appreciation scale. As Table 1 demonstrates, mean scores were the highest in the third year for five of the six questions informing about understanding. Only the means score for the item regarding clarity of which material could be included in the portfolio stayed the same.

We also investigated whether the scores on these scales increased or decreased during the 3 years of our study. We found that the scores on both scales increased significantly in this period $(p<.001)$. We established a correlation of .25 between Understanding and Year of completing the questionnaire. We found a correlation of .23 between Appreciation and Year of completing the questionnaire (both $p<.001)$. Table 2 reveals that mean appreciation of the portfolio and its use was highest in year 3 .

\section{Conclusion and discussion}

In our study, we examined whether using an analogy when introducing a portfolio helps students understand both the purpose of using a portfolio and how to compile it. By using an analogy, we linked a new concept, the portfolio, to a concept with which the students were already familiar, the documents and references that are commonly used in a selection procedure for new employees in the Netherlands. We also investigated whether there is a correlation between the students' understanding and their appreciation of the portfolio and its use.

We conclude that a portfolio introduction in which an analogy is used was helpful for promoting students understanding. However, teacher educators and some students noted that very often it took some time to work with the portfolio and discuss it with fellow students and teacher educators before students really understood the purpose of working with a portfolio and what it should contain. It is also important that the understanding of students increased in the 3 years in which we gathered data. This implies that although students' understanding has improved compared with the situation before an analogy was used, the improvement can not be attributed to the use of the analogy in the introduction alone. We did not investigate the teacher educators' understanding of the portfolio and their routine in introducing the portfolio using the analogy, but this understanding probably grew with their experience. This may account for the improvement in student understanding too. This implies that the teacher educators' experience is a significant factor for a clear introduction as well. This conclusion suggests that it is important that teacher educators and researchers collaborate on developing the portfolio and its introduction, as was the case in the project described here. Co-developing not only stimulates ownership of the portfolio project by the teacher educators, but undoubtedly also leads to better understanding of the purpose of working with a portfolio and how to introduce it by means of an analogy.

We established a strong correlation between students' understanding and their appreciation of the use of portfolios in this teacher education programme. This is important because students who understand the why and how of a portfolio and appreciate its use will probably be more willing to invest time in using this instrument. According to Wade and Yarbrough (1996), investing this time is a major factor for successful use of the portfolio for developmental purposes. Another factor contributing to willingness to put time and energy in the portfolio is a feeling of ownership. Freedom in deciding how to put together a portfolio is important for this feeling of ownership too (Borko et al., 1997; Wade \& Yarbrough, 1996). But it is also important that teacher educators do not have to discover how to navigate through each new creatively designed and structured portfolio. In selection procedures the tension between freedom for the applicant and ease of use for the selection committee is solved, because applicants usually stick to implicit conventions about how to write and structure letters of application and CVs. These conventions are known by most people but are not formally prescribed. This leaves room for applicants to give these documents a personal touch expressing their personality, but they are careful not to cross any line that would distract a selection committee. 
By using the analogy of the portfolio with these documents, we hoped to stimulate students to stick to conventions which would keep the portfolio accessible to others, but at the same time leave room for a personal touch which would promote a feeling of ownership. The students' spontaneous remarks about the freedom they experienced in putting together the portfolio are encouraging in this light.

Although we conclude that an analogy can be helpful to stimulate understanding, we do not want to advocate the use of this specific analogy for other programmes, without first carefully scrutinizing whether this analogy matches with the portfolio system that is used. Portfolios can differ considerably depending on the purpose of their use (van Tartwijk et al., 2007) Portfolios can be used for assessment purposes (Peterson, 1995) for monitoring and planning the development of competence (Snadden, Challis, \& Thomas, 1999), for stimulating reflection (Mansvelder-Longayroux et al., 2007) or for a combination of these purposes (Snyder et al., 1998; Wolf \& Dietz, 1998). As a consequence, the analogy of a portfolio with the documents and references that are commonly used in job application procedures is not self-evident, and another analogy may be a better choice. Using an analogy can be helpful to promote understanding, but only if the analogue and the target domain match.

Portfolios can be powerful instruments to stimulate reflective practice (Borko et al., 1997) and can also be used for authentic assessment of teaching in context (Darling-Hammond \& Snyder, 2000). However, their use in teacher education is complicated and can easily lead to disappointment. One of the problems that teacher educators encounter is that often students do not understand what a portfolio is and how or work with it. In this study it was found that an analogy can be useful to foster students' understanding. In turn, students' understanding relates to their ability to appreciate the benefits of portfolios. This appreciation is probably related to student commitment and willingness to invest in working with a portfolio, which is condition for a successful use of portfolios in teacher education as tools for stimulating reflective practice and authentic assessment of learning in context.

\section{References}

Anderson, R. S., \& DeMeulle, L. (1998). Portfolio use in twentyfour teacher education programs. Teacher Education Quarterly, 25(1), 23-32.
Beijaard, D., Meijer, P., \& Verloop, N. (2004). Reconsidering research on teachers' professional identity. Teaching and Teacher Education, 20(2), 107-128.

Borko, H., Michalec, P., Timmons, M., \& Siddle, J. (1997). Student teaching portfolios: A tool for promoting reflective practice. Journal of Teacher Education, 48(5), 345-357.

Breault, R. A. (2004). Dissonant themes in preservice portfolio development. Teaching and Teacher Education, 20(8), 847-859.

Carroll, J. A., Potthoff, D., \& Huber, T. (1996). Learnings from three years of portfolio use in teacher education. Journal of Teacher Education, 47(4), 253-262.

Darling, L. F. (2001). Portfolio as practice: The narratives of emerging teachers. Teaching and Teacher Education, 17(1), $107-121$.

Darling-Hammond, L., \& Snyder, J. (2000). Authentic assessment of teaching in context. Teaching and Teacher Education, 16(5-6), 523-545.

Duit, R., Roth, W.-M., Komorek, M., \& Wilbers, J. (2001). Fostering conceptual change by analogies-Between Scylla and Charybdis. Learning and Instruction, 11(4-5), 283-303.

Duque, G., Finkelstein, A., Robert, A., Tabatabia, D., Gold, S. L., \& Winer, L. R. (2006). Learning while velauating: The use of an electronic evaluation portfolio in a geraitric medicine clerckship. BMC Medical Education, 6(1), 1-7.

Hulshof, H., \& Verloop, N. (2005). Do teachers need instructional analogies to teach mother-tongue (L1)-Teachers' perceptions and representations of difficult topics in mothertongue education. Educational studies in language and literature, 5, 23-27.

Korthagen, F. A. J., Kessels, J., Koster, B., Lagerwerf, B., \& Wubbels, T. (2001). Linking theory and practice: The pedagogy of realistic teacher education. Mahwah, NY: Lawrence Erlbaum Associates.

Krause, S. (1996). Portfolios in teacher education: Effects of instruction on preservice teachers' early comprehension of the portfolio process. Journal of Teacher Education, 47(2), 130-138.

Mansvelder-Longayroux, D. D., Beijaard, D., \& Verloop, N. (2007). The portfolio as a tool for stimulating reflection by student teachers. Teaching and teacher education, 23(1), 47-62.

Orgill, M., \& Bodner, G. (2004). What research tells us about using analogies to teach chemistry. Chemistry and Education: Research and Practice, 5(1), 15-32.

Pecheone, R. L., \& Chung, R. R. (2006). Evidence in teacher education: The performance assessment for California teachers. Journal of Teacher Education, 57(1), 22-36.

Peterson, K. D. (1995). Teacher evaluation: A comprehensive guide to new directions and practices. Thousand Oaks, CA: Corwin Press, Inc.

Shulman, L. S. (1998). Teacher portfolios: A theoretical activity. In N. Lyons (Ed.), With portfolio in hand: Validating the new teacher professionalism (pp. 23-38). New York: Teachers College Press.

Snadden, D., Challis, M., \& Thomas, M. (1999). Portfolio-based learning and assessment: The use of portfolio-based learning in medical education (No. 11). Dundee: University of Dundee.

Snyder, J., Lippincott, A., \& Bower, D. (1998). The inherent tensions in the multiple uses of portfolios in teacher education. Teacher Education Quarterly, 25(1), 45-60.

Stokking, K., Leenders, F., de Jong, J., \& Van Tartwijk, J. (2003). From student to teacher: Reducing practice shock and 
early dropout in teacher education. European Journal of Teacher Education, 26(3), 329-350.

Tigchelaar, A., \& Korthagen, F. A. J. (2004). Deepening the exchange of student teaching experiences: Implications for the pedagogy of teacher education of recent insights into teacher behaviour. Teaching and Teacher Education, 30(4), 665-679.

Tillema, H., \& Smith, K. (2007). Portfolio appraisal: In search of criteria. Teaching and Teacher Education, 23(4), 442-456.

van Tartwijk, J., Driessen, E., Stokking, K., \& van der Vleuten, C. (2007). Factors influencing the successful introduction of portfolios. Quality in Higher Education., 13(1), 69-79.

Wade, R. C., \& Yarbrough, D. B. (1996). Portfolios: A tool for reflective thinking in teacher education. Teaching and Teacher Education, 12(1), 63-79.
Wolf, K. (1991). The schoolteacher's portfolio: Issues in design, implementation and evaluation. Phi Delta Kappan, 73, 129-136.

Wolf, K., \& Dietz, M. (1998). Teaching portfolios: Purposes and possibilities. Teacher Education Quarterly, 25(1), 9-22.

Wubbels, T., Brekelmans, M., den Brok, P., \& van Tartwijk, J. (2006). An interpersonal perspective on classroom management in secondary classrooms in the Netherlands. In C. Evertson, \& C. Weinstein (Eds.), Handbook of classroom management: Research, practice, and contemporary issues (pp. 1161-1191). Mahwah, NJ: Lawrence Erlbaum Associates.

Zeichner, K., \& Wray, S. (2001). The teaching portfolio in US teacher education programs: What we know and what we need to know. Teaching and Teacher Education, 17(5), 613-621. 